\title{
Patient Characteristics and Indicators of Treatment Initiation with Repository Corticotropin Injection in Patients with Rheumatoid Arthritis: A Claims Database Analysis
}

\author{
Kyle Hayes (D) · Mary P. Panaccio · Niti Goel · Mohammed Fahim
}

Received: November 11, 2020 / Accepted: December 11, 2020 / Published online: January 5, 2021

(c) The Author(s) 2021

\begin{abstract}
Repository corticotropin injection (RCI) is indicated as adjunctive, short-term therapy in selected patients with RA. To characterize RCI users and identify predictors of RCI initiation in RA, we compared preindex characteristics, treatment patterns, comorbidities, healthcare resource utilization (HCRU), and costs for patients who had initiated RCI treatment (RCI cohort) versus patients with no RCI claims and $\geq 1$ targeted synthetic or biologic diseasemodifying antirheumatic drugs (ts/bDMARD) claim (non-RCI ts/bDMARD cohort). We analyzed pharmacy and medical claims data from a large commercial and Medicare supplemental administrative database. Inclusion criteria were
\end{abstract}

Supplementary Information The online version contains supplementary material available at https:// doi.org/10.1007/s40744-020-00272-x.

K. Hayes $(\bowtie)$

Mallinckrodt Pharmaceuticals, Hazelwood, MO, USA

e-mail: kyle.hayes@mnk.com

M. P. Panaccio

Mallinckrodt Pharmaceuticals, Bedminster, NJ, USA

N. Goel

Caduceus Biomedical Consulting, LLC, Durham,

NC, USA

M. Fahim

KMK Consulting, Morristown, NJ, USA age $\geq 18$ years, $\geq 1$ inpatient or $\geq 2$ outpatient claims with RA diagnosis (January 1, 2007-December 31, 2018), and 12-month continuous medical and pharmacy coverage preindex. Results from baseline cohort comparisons informed multiple logistic regression analysis. Compared with the non-RCI ts/bDMARD cohort $(n=162,065)$, the RCI cohort $(n=350)$ had a greater proportion of patients with higher Charlson comorbidity index (CCI) scores; higher mean claims-based index of RA severity and CCI scores; greater frequency of almost all comorbidities; higher use of nontraditional DMARDs, glucocorticoids, and opioids; higher all-cause HCRU; and higher medical and total costs. By multivariable analysis, the most significant predictors of RCI initiation were intermittent glucocorticoid use at any dose (odds ratio [OR] 1.67), extended-use glucocorticoids at medium (OR 2.03) and high doses (OR 2.99), nontraditional DMARD use (OR 2.09), anemia (OR 1.39), and renal disease (OR 2.45). Before RCI initiation, patients had more severe RA, higher comorbidity burden, greater use of glucocorticoids and opioids, and higher HCRU compared with non-RCI initiators. The most significant predictors for starting RCI in patients with RA were intermittent use of glucocorticoids at any dose, extended-use high-dose glucocorticoids, use of nontraditional DMARDs, and comorbid anemia and renal disease. 
Keywords: ACTH; Acthar ${ }^{\circledR}$ Gel; Glucocorticoids; Healthcare utilization; RCI; Repository corticotropin injection; Rheumatoid arthritis

\section{Key Summary Points}

\section{Why carry out this study?}

An estimated $6 \%$ of people living with moderate-to-severe rheumatoid arthritis (RA), approximately 30,000 to 34,000 US patients, are refractory to targeted diseasemodifying antirheumatic drug (DMARD) therapies and in need of alternatives to manage uncontrolled disease.

Repository corticotropin injection (RCI; Acthar $^{\circledR}$ Gel) is approved by the U.S. Food and Drug Administration as an adjunctive therapy for short-term administration (to tide the patient over an acute episode or exacerbation) and for use in "selected cases who may require low-dose maintenance therapy" for RA.

To characterize patients best suited for RCI therapy and identify predictors of RCI initiation, we performed a retrospective claims database analysis comparing patients who had initiated RCI therapy with patients who had not initiated RCI therapy and who were being treated with at least 1 targeted synthetic or biologic DMARD (ts/bDMARD).

\section{What was learned from the study?}

There remains an unmet need for patients with refractory, persistently active RA who do not tolerate or respond to current treatment options. Patients who initiated RCI had higher comorbidity burden and more severe disease than those who did not, and they had previously tried a myriad of treatments (DMARDs, highdose glucocorticoids, opioids, nonsteroidal anti-inflammatory drugs).

\section{Significant predictors for RCI therapy} initiation in patients with RA were prior treatment with high-dose or extended-use glucocorticoids and nontraditional DMARDs as well as comorbid anemia and renal disease.

This study identifies a potentially significant subset of patients with RA in whom RCI therapy appears to have a role in their disease management.

\section{DIGITAL FEATURES}

This article is published with digital features, including a summary slide, to facilitate understanding of the article. To view digital features for this article go to https://doi.org/10.6084/ m9.figshare.13353419.

\section{INTRODUCTION}

Rheumatoid arthritis (RA) is a chronic autoimmune joint disease characterized by inflammatory responses that can cause cartilage and bone destruction, leading to disability, reduced quality of life, and an increased risk of extraarticular manifestations [1]. In addition, RA and other forms of arthritis cause a considerable societal economic burden [2-4]. The total incremental cost to treat all patients with RA in the United States was estimated to be $\$ 22.3$ billion in 2008 [2].

Use of targeted disease-modifying antirheumatic drug (DMARD) therapy has shown great benefit in many patients with moderate-tosevere RA. Both the American College of Rheumatology (ACR) [5] and European League Against Rheumatism (EULAR) [4] recommend a treat-to-target approach for RA [1]. Nonetheless, some patients with RA do not respond to current and recommended first-, second-, or thirdline treatments $[5,6]$. Although exact estimates of the number of patients with refractory or uncontrolled RA are unavailable, a recent study 
from the British Society for Rheumatology Biologics Register for RA found that $6 \%$ of all patients who initiated first-line bDMARD therapy (with tumor necrosis factor [TNF] inhibitors) still did not respond after trying three classes of bDMARDs and were classified as having refractory disease [7]. These estimates translate to approximately 30,000-34,000 US patients with uncontrolled RA in need of other treatment options $[8,9]$. Factors to consider in alternative treatment selection include disease activity, comorbidities, patterns of response to previous treatments, prescription drug coverage, patient cost burden, and adherence [6, 10-14].

Repository corticotropin injection (RCI; Acthar ${ }^{\circledR}$ Gel, Mallinckrodt ARD LLC, Bedminster, NJ, USA)—a naturally sourced complex mixture of adrenocorticotropic hormone analogs and other pituitary peptides-is indicated for short-term administration in patients experiencing acute episodes or exacerbations of RA [15]. Evidence from previous studies suggests that in clinical practice, RCI is used primarily as late-line therapy to treat flares, as a bridge to new therapy, or as an add-on to prior therapy $[16,17]$.

Though RCI has demonstrated efficacy in treating a subset of patients with RA refractory to the most common treatments [18], an accurate profile of these patients is lacking in the current literature. To help fill this gap, we conducted a retrospective administrative claim database analysis to (1) describe patient clinical characteristics, treatment patterns, and healthcare resource utilization (HCRU) in the 12 months before the index date (preindex period, defined below); (2) identify predictors of RCI initiation by comparing a cohort of patients with RA who initiated RCI therapy with a cohort of patients treated with ts/bDMARDs without any claims for RCI; and (3) compare predictors of RCI initiation in a subgroup of the study population, limited to patients who tried at least one targeted DMARD during the preindex period.

\section{METHODS}

\section{Study Design and Data Source}

This retrospective cohort study evaluated predictors of RCI treatment initiation in adults $\left(\geq 18\right.$ years) with RA using data from the $\mathrm{IBM}^{\circledR}$ MarketScan ${ }^{\circledR}$ Commercial Claims and Encounters (CCAE) and Medicare Supplemental and Coordination of Benefits (COB) research databases for the period of January 1, 2007-December 31, 2018. These databases contain deidentified, person-specific health data including clinical utilization, expenditures, insurance enrollment/plan benefit, inpatient, outpatient, and prescription information. Together, the CCAE and Medicare Supplemental databases include the records of more than 66 million people [19]. These patients have coordination of benefits, meaning that in addition to Medicare, they have a private insurance plan paid for by their employers and therefore are not typical of the usual Medicare patient population. The Medicare Supplemental and $\mathrm{COB}$ dataset contains information on both Medicare-paid and supplemental insurancepaid services.

This article is based on previously existing observational data, and the research did not involve any new interventional studies of human or animal subjects performed by any of the authors. This retrospective study used deidentified data, and no personal health information was collected. For this type of study, formal consent was not required. Because of the retrospective study design using previously collected deidentified data, institutional review board approval was not necessary for this study.

\section{Patient Identification}

The study population included adults (age $\geq 18$ years) with $\geq 1$ inpatient or $\geq 2$ outpatient claims with non-rule out International Classification of Diseases, Ninth or 10th Revision (ICD-9/10) RA diagnosis during the January 1, 2007, to December 31, 2018, study intake period and with 12 months of continuous medical and pharmacy coverage before the 


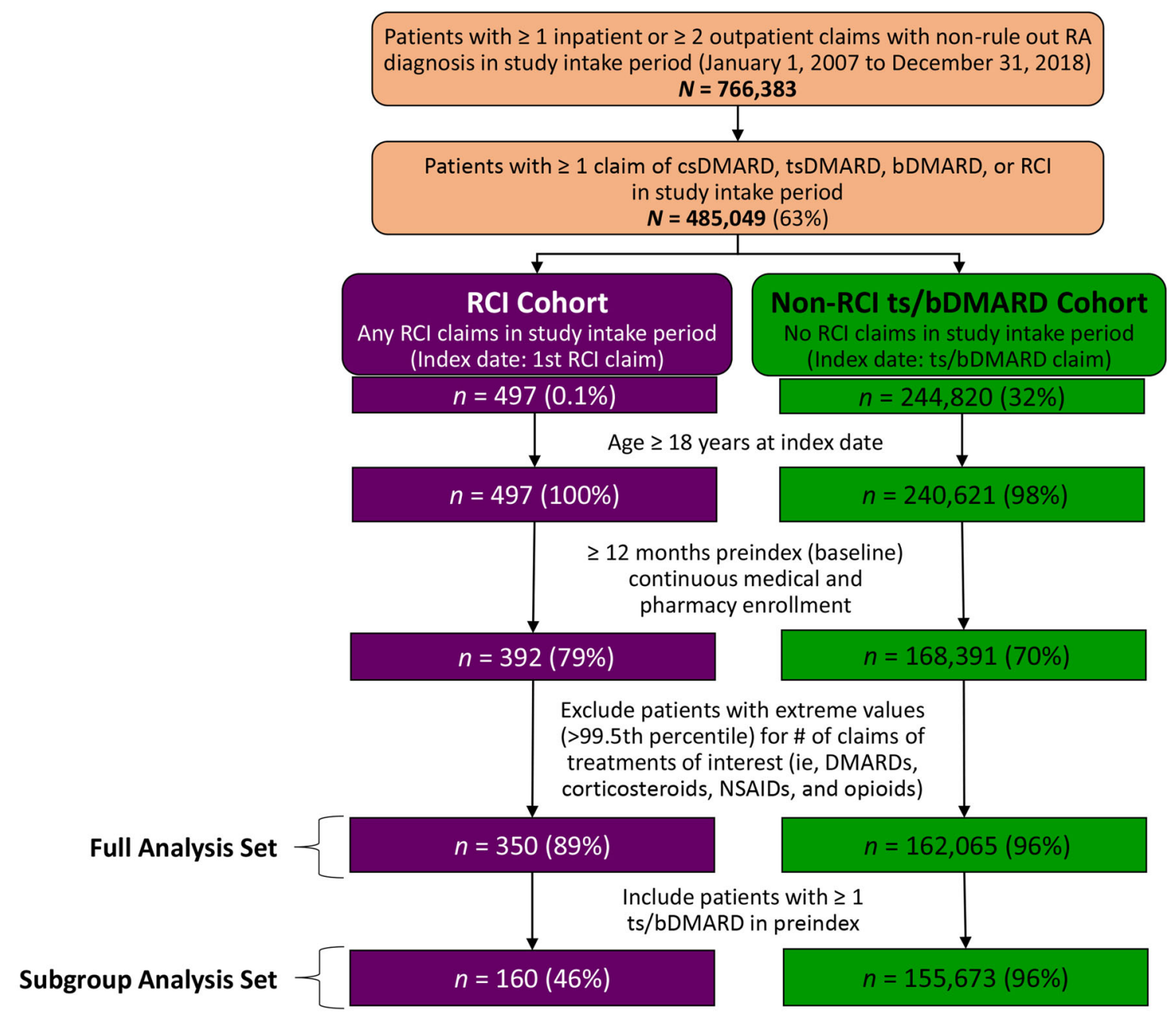

Fig. 1 Flow diagram of the selection process used to form the study cohorts for the full and subgroup analyses. $D M A R D$ disease-modifying antirheumatic drug, NSAID nonsteroidal anti-inflammatory $\mathrm{drug}, R A$ rheumatoid

index date. The index date was the date of the first RCI claim for the RCI cohort and the date of the last ts/bDMARD claim for the non-RCI ts/ bDMARD cohort. We selected the index date of last ts/bDMARD to obtain a patient population more likely to have established or chronic RA and to minimize the number of patients with early disease who were just initiating targeted DMARD therapy. Patients who initiate RCI therapy are generally required by payers to have tried multiple other treatment options before initiation, which suggests more established RA, similar to the non-RCI ts/bDMARD cohort. arthritis, $R C I$ repository corticotropin injection, $t s / b$ targeted synthetic/biologic

To be included in a study cohort, patients had to have $\geq 1$ claim for an RA-related tsDMARD, bDMARD, or RCI. The RCI cohort comprised patients with $\mathrm{RA}$ and $\geq 1$ claim for RCI during the study index period. The non-RCI ts/bDMARD cohort comprised patients without any claims for RCI and $\geq 1$ claim for a ts/ bDMARD during the study index period. The RCI cohort and the non-RCI ts/bDMARD cohort comprised the full analysis set. In both cohorts (Fig. 1), we excluded patients (RCI: $n=42$, 10.7\%; non-RCI: $n=6326,3.7 \%$ ) with extreme values ( $>99.5$ th percentile) for the number of claims of treatments of interest [i.e., DMARDs, 
glucocorticoids, nonsteroidal anti-inflammatory drugs (NSAIDs), or opioids].

We conducted a subgroup analysis of patients from both full analysis set cohorts who had $\geq 1$ claim for a ts/bDMARD in the preindex period. The purpose of this subgroup analysis was to directly compare patients who currently (or recently) had used ts/bDMARDs with beneficial results and continued that therapy (nonRCI ts/bDMARD cohort) with patients who had poor response and had initiated RCI treatment (RCI cohort). While, as a result of this cohort's inclusion criteria, almost all patients in the full analysis set ts/bDMARD cohort had targeted DMARD therapy in the preindex period, it is likely that most patients in the full analysis RCI cohort had previously tried ts/bDMARD therapy but may have discontinued treatment before the preindex period, which is not captured in the full analysis set.

\section{Variables and Outcome Measures}

Analyzed descriptive statistics included index demographic characteristics (i.e., sex, age, health plan type, insurance type, geographic region, year of index date), preindex clinical characteristics (i.e., preexisting conditions, RA severity score), medication use, HCRU, and costs. To determine the geographic region, we used the Federal Information Processing Standard Publication codes in the databases for states and regions defined according to the US 2010 census [20]. The RA severity measures used in the dataset were the claims-based diseasespecific refinements (CDMF) Charlson comorbidity index (CCI) and claims-based index of RA severity (CIRAS) [21, 22]. Tables S1 and S2 in the electronic supplementary materials list the ICD9/10 codes we used to define CIRAS and CCI.

We used Andersen's Behavioral Model (ABM) of healthcare utilization for grouping predictors of treatment initiation. $\mathrm{ABM}$ is a validated conceptual model for describing factors that influence or predict HCRU as predisposing, enabling, or need [23, 24]. The predisposing factors that we used were age, sex, and region in the United States. The enabling factors were insurance type (commercial or Medicare supplemental), plan type (capitated or noncapitated), RA severity index (CIRAS), comorbidity index (CDMF-CCI), number of physician visits [inpatient, emergency department (ED), office, other outpatient]. The need factors were the number of preindex csDMARD claims, the number of preindex ts/bDMARD claims, preindex pain indicators (number of NSAID/opioid claims), preindex glucocorticoid claims, glucocorticoid treatment type (doses as defined below) within 60 days of the preindex date, and select individual comorbidities at index. Aligning with the work by Chen et al. [25] and Rice et al. $[26,27]$, we used the following definitions to describe glucocorticoid treatment: intermittent ( $<60$ days) or extended ( $\geq 60$ days) at low ( $\leq 7.5 \mathrm{mg} /$ day), medium ( $>7.5-\leq 15 \mathrm{mg} /$ day), or high ( $>15 \mathrm{mg} /$ day) doses. For patients with extended-use glucocorticoids, the average daily dose (ADD) was also calculated. Supplementary Tables S3 and S4 provide the ICD codes used to define select comorbidities and treatments, respectively.

To better understand differences in treatment patterns, we divided csDMARDs into two groups: (1) csDMARDs currently used and recommended in ACR/EULAR guidelines, referred to as "traditional" DMARDs in this study (hydroxychloroquine sulfate, leflunomide, methotrexate, sulfasalazine), and (2) csDMARDs that are not recommended by current ACR/ EULAR guidelines, yet still used infrequently in typically hard-to-treat patients, referred to as "nontraditional" DMARDs (azathioprine, cyclophosphamide, cyclosporine, mycophenolate mofetil) (Supplementary Table S4).

\section{Statistical Analyses}

Because of the descriptive nature of the study, sample size was not based on formal statistical hypothesis testing. All patients who met the eligibility criteria were included in the analysis. We presented descriptive statistics as mean and standard deviation (SD) for continuous variables and as number of patients and percentage for categorical variables.

In addition to the descriptive characterization of the RCI patient population, we used 
multiple logistic regression to identify the most significant predictors of RCI initiation in the full RCI and non-RCI ts/bDMARD cohorts as well as in the subgroup analysis of patients with at least one claim for a ts/bDMARD in the preindex period, as described above. We analyzed baseline (index) demographics, preindex clinical characteristics, and treatment patterns. To assess the statistical significance of possible predictors of RCI initiation, we conducted a univariate analysis using RCI as the dependent variable and each individual covariate as an independent variable, with a two-tailed significance level of alpha $=0.05$. Factors that were identified as significant in the univariate analysis, along with relevant demographic and clinical characteristics, were included in the multiple logistic regression analysis.

\section{RESULTS}

\section{Cohort Selection}

Based on the selection criteria shown in Fig. 1, a total of 766,383 RA patients were identified with $\geq 1$ inpatient or $\geq 2$ outpatient claims with non-rule out ICD-9/10 RA diagnosis during the study intake period (Fig. 1). Among these patients, 485,049 had $\geq 1$ claim for an RA-related medication of interest (csDMARD, tsDMARD, bDMARD, or RCI). The full analysis comprised 350 patients in the RCI cohort and 162,065 patients in the non-RCI ts/bDMARD cohort; Table 1 summarizes the baseline demographic and clinical characteristics of the full analysis set. Both cohorts had a mean age of 56 years and a similar proportion of female patients, $78 \%$ and $76 \%$ in the RCI and non-RCI ts/bDMARD cohorts, respectively. Patients in the RCI cohort were primarily located in the South (36\%) and the Northeast (31\%) regions of the United States; patients in the non-RCI ts/ bDMARD cohort were primarily located in the South (43\%) and North Central (22\%) regions. In both the RCI and non-RCI ts/bDMARD cohorts, most patients had commercial insurance coverage (77 and $81 \%$, respectively) provided by fee-for-service plans (91 and 85\%, respectively). The RCI cohort had a higher
Table 1 Baseline demographic and clinical characteristics of patients in the full analysis set

\begin{tabular}{llrl}
\hline Characteristic & $\begin{array}{l}\text { RCI } \\
\text { cohort } \\
(\boldsymbol{n}=\mathbf{3 5 0})\end{array}$ & $\begin{array}{l}\text { Non-RCI ts/ } \\
\text { bDMARD } \\
\text { cohort } \\
(\boldsymbol{n}=\mathbf{1 6 2 , 0 6 5})\end{array}$ & $\boldsymbol{P}$ value \\
\hline $\begin{array}{l}\text { Mean age, } \\
\text { years (SD) }\end{array}$ & $56.0(13.5)$ & $56.4(13.5)$ & 0.551 \\
$\begin{array}{l}\text { Sex, } n \text { (\%) } \\
\text { Female }\end{array}$ & $273(78.0)$ & $123,314(76.1)$ & 0.403
\end{tabular}

Geographic region, $n$ (\%)

$\begin{array}{lccl}\text { Northeast } & 107(30.6) & 26,029(16.1) & \text { Reference } \\ \begin{array}{l}\text { North } \\ \text { Central }\end{array} & 66(18.9) & 36,464(22.5) & <0.001 \\ \text { South } & 126(36.0) & 69,712(43.0) & <0.001 \\ \text { West } & 46(13.1) & 27,604(17.0) & <0.001 \\ \text { Unknown } & 5(1.4) & 2256(1.4) & 0.1771 \\ \text { Insurance type, } n(\%) & & \\ \text { Commercial } & 270(77.1) & 131,016(80.8) & \text { Reference } \\ \begin{array}{l}\text { Medicare } \\ \text { supplemental }\end{array} & 80(22.9) & 31,049(19.2) & 0.080\end{array}$

Plan type, $n(\%)$

$\begin{array}{lrrl}\begin{array}{l}\text { Fee-for- } \\ \text { service }\end{array} & 319(91.1) & 138,378(85.4) & \text { Reference } \\ \text { Capitation } & 22(6.3) & 17,702(10.9) & 0.005 \\ \text { Unknown } & 9(2.6) & 5985(3.7) & 0.207 \\ \begin{array}{l}\text { CDMF-CCI, } \\ \text { mean (SD) }\end{array} & 1.9(1.4) & 1.6(1.2) & <0.001 \\ \text { CDMF-CCI group, } n(\%) & & \\ 0 & 26(7) & 7958(5) & \text { Reference } \\ 1-2 & 231(66) & 129,025(80) & 0.004 \\ 3-4 & 72(21) & 19,714(12) & 0.627 \\ 5+ & 21(6) & 5368(3) & 0.539 \\ \text { CIRAS, mean } & 5.78(1.94) & 5.44(1.70) & <0.001\end{array}$

(SD)

Index year, $n(\%)$

$2008 \quad 12(3.4) \quad 5967(3.7) \quad$ Reference


Table 1 continued

\begin{tabular}{llll}
\hline Characteristic & $\begin{array}{l}\text { RCI } \\
\text { cohort } \\
(\boldsymbol{n}=\mathbf{3 5 0})\end{array}$ & $\begin{array}{l}\text { Non-RCI ts/ } \\
\text { bDMARD } \\
\text { cohort } \\
(\boldsymbol{n}=\mathbf{1 6 2 , 0 6 5})\end{array}$ & $\boldsymbol{P}$ value \\
\hline 2009 & $5(1.4)$ & $10,023(6.2)$ & 0.009 \\
2010 & $14(4.0)$ & $10,189(6.3)$ & 0.333 \\
2011 & $5(1.4)$ & $11,235(6.9)$ & 0.005 \\
2012 & $28(8.0)$ & $20,148(12.4)$ & 0.285 \\
2013 & $62(17.7)$ & $13,314(8.2)$ & 0.008 \\
2014 & $87(24.9)$ & $18,788(11.6)$ & 0.007 \\
2015 & $55(15.7)$ & $9812(6.1)$ & 0.001 \\
2016 & $45(12.9)$ & $13,586(8.4)$ & 0.125 \\
2017 & $23(6.6)$ & $13,794(8.5)$ & 0.600 \\
2018 & $14(4.0)$ & $35,209(21.7)$ & $<0.001$ \\
\hline
\end{tabular}

$C C I$ Charlson comorbidity index, $C D M F$ claims-based disease-specific refinements, CIRAS claims-based index of rheumatoid arthritis severity, DMARD disease-modifying antirheumatic drug, $R C I$ repository corticotropin injection, $S D$ standard deviation, $t s / b$ targeted synthetic/ biologic

proportion of patients in CDMF-CCI group 3-4 ( 21 vs. $12 \%)$ and group $\geq 5$ (6 vs. $3 \%$ ) compared with the non-RCI ts/bDMARD cohort, respectively.

The subgroup analysis set of patients with $\geq 1$ claim for a ts/bDMARD comprised 160 patients in the RCI cohort and 155,673 patients in the non-RCI ts/bDMARD cohort (Fig. 1). Table S5 in the electronic supplementary materials summarizes the baseline demographic and clinical characteristics for the cohorts in the subgroup analysis set, the results of which were similar to the full analysis set. Unless otherwise indicated, the findings presented in this report are from the full analysis set.

Table 2 summarizes the bivariate analysis of comorbidities reported in $\geq 5 \%$ of patients in either cohort in the full analysis set. The RCI cohort had a statistically significant higher prevalence of several comorbidities than the non-RCI ts/bDMARD cohort including anemia (26 vs. $12 \%$ ), arrhythmia (18 vs. 9\%), cerebrovascular disease/stroke (7 vs. $4 \%$ ), deep vein thrombosis (5 vs. 1\%), hypertension (51 vs. $41 \%)$, ischemic heart disease (15 vs. $9 \%$ ), diabetes with complication (16 vs. $11 \%$ ), mild or moderate renal disease (13 vs. $4 \%$ ), anxiety (14 vs. $11 \%$ ), depression ( 20 vs. $14 \%$ ), arthralgia (49 vs. $36 \%)$, carpal tunnel syndrome (7 vs. $4 \%$ ), Sjögren's syndrome (6 vs. $2 \%$ ), synovitis (9 vs. $6 \%$ ), chronic pulmonary disease (27 vs. $16 \%$ ), pulmonary embolism (5 vs. $1 \%$ ), cataract (19 vs. $14 \%)$, and general infection (35 vs. $29 \%$ ).

\section{Treatment Pattern}

Figure 2 summarizes the general treatment pattern of the cohorts. Overall, RCI patients used more nontraditional DMARDs (14 vs. $2 \%$ ), glucocorticoids ( 90 vs. $68 \%$ ), NSAIDs ( 65 vs. $57 \%$ ), and opioids (66 vs. 45\%) compared with patients in the non-RCI ts/bDMARD cohort during their preindex period (Fig. 2). Patients in the non-RCI ts/bDMARD cohort were more likely to have received targeted DMARDs (96 vs. $46 \%$ ) and nearly just as likely to have received traditional DMARDs (63 vs. 58\%) compared with patients in the RCI cohort, respectively.

Patients in the RCI cohort tried significantly more drugs within the medication class and filled more prescriptions overall for nontraditional DMARDs, glucocorticoids, NSAIDs, and opioids (Fig. 3a, b), compared with the non-RCI ts/bDMARD cohort. Although there was no difference in the mean number of different traditional DMARDs tried, the non-RCI ts/ bDMARD cohort filled significantly more traditional DMARD prescriptions compared with the RCI cohort. Patients in the non-RCI ts/bDMARD cohort had a significantly greater mean number of ts/bDMARDs tried within the class and filled more ts/bDMARDs than the RCI cohort during the preindex period (Fig. 3a, b). As shown in the electronic supplementary materials, in the subgroup analysis of patients who had tried a ts/ bDMARD in the preindex period, the RCI cohort had a significantly higher mean number of ts/bDMARDs tried (Fig. S1a) but a 
Table 2 Comorbidities by cohort in the full analysis set

\begin{tabular}{|c|c|c|c|c|}
\hline Comorbidity, $n$ (\%) & $\begin{array}{l}\text { RCI cohort } \\
(n=350)\end{array}$ & $\begin{array}{l}\text { Non-RCI ts/bDMARD cohort } \\
(n=162,065)\end{array}$ & $\begin{array}{l}\text { OR }(95 \% \\
\text { CI })^{\mathrm{a}}\end{array}$ & $P$ value \\
\hline \multicolumn{5}{|l|}{ Cancer } \\
\hline Malignancy & $23(6.6)$ & $11,689(7.2)$ & $\begin{array}{l}0.91 \\
\quad(0.56-1.47)\end{array}$ & 0.905 \\
\hline Nonmalignant & $86(24.6)$ & $34,440(21.3)$ & $\begin{array}{l}1.21 \\
\quad(0.91-1.60)\end{array}$ & 0.128 \\
\hline \multicolumn{5}{|l|}{ Cardiovascular/circulatory } \\
\hline Anemia & $91(26.0)$ & $20,041(12.3)$ & $\begin{array}{l}2.50 \\
\quad(1.90-3.28)\end{array}$ & $<0.001$ \\
\hline Arrhythmia & $62(17.7)$ & $15,060(9.3)$ & $\begin{array}{l}2.10 \\
\quad(1.54-2.88)\end{array}$ & $<0.001$ \\
\hline Cerebrovascular disease/stroke & $24(6.9)$ & $6401(3.9)$ & $\begin{array}{l}1.79 \\
\quad(1.11-2.88)\end{array}$ & 0.006 \\
\hline Deep vein thrombosis & $18(5.1)$ & $1986(1.2)$ & $\begin{array}{l}4.38 \\
\quad(2.54-7.54)\end{array}$ & $<0.001$ \\
\hline $\begin{array}{l}\text { Hypercholesterolemia, hyperlipidemia, } \\
\text { or triglyceridemia }\end{array}$ & $109(31.1)$ & $46,360(28.6)$ & $\begin{array}{l}1.13 \\
\quad(0.87-1.46)\end{array}$ & 0.291 \\
\hline Hypertension & $178(50.8)$ & $66,270(40.9)$ & $\begin{array}{l}1.50 \\
\quad(1.18-1.91)\end{array}$ & $<0.001$ \\
\hline Ischemic heart disease & $52(14.8)$ & $14,104(8.7)$ & $\begin{array}{l}1.83 \\
\quad(1.31-2.57)\end{array}$ & $<0.001$ \\
\hline \multicolumn{5}{|l|}{ Endocrine/metabolic } \\
\hline Diabetes with complication & $57(16.3)$ & $17,766(11.0)$ & $\begin{array}{l}1.58 \\
\quad(1.14-2.19)\end{array}$ & 0.002 \\
\hline Diabetes without complication & $25(7.1)$ & $10,842(6.7)$ & $\begin{array}{l}1.07 \\
(0.67-1.71)\end{array}$ & 0.732 \\
\hline Obesity & $48(13.7)$ & $22,037(14.0)$ & $\begin{array}{l}1.01 \\
\quad(0.71-1.48)\end{array}$ & 0.945 \\
\hline Renal disease (mild, moderate) & $44(12.6)$ & $6933(4.3)$ & $\begin{array}{l}3.22 \\
\quad(2.24-4.63)\end{array}$ & $<0.001$ \\
\hline \multicolumn{5}{|l|}{ Mental health } \\
\hline Anxiety & $50(14.3)$ & $17,188(10.6)$ & $\begin{array}{l}1.41 \\
\quad(1.00-1.98)\end{array}$ & 0.026 \\
\hline Depression & $71(20.3)$ & $22,912(14.1)$ & $\begin{array}{l}1.55 \\
\quad(1.15-2.09)\end{array}$ & 0.001 \\
\hline
\end{tabular}


Table 2 continued

\begin{tabular}{|c|c|c|c|c|}
\hline Comorbidity, $n$ (\%) & $\begin{array}{l}\text { RCI cohort } \\
(n=350)\end{array}$ & $\begin{array}{l}\text { Non-RCI ts/bDMARD cohort } \\
(n=162,065)\end{array}$ & $\begin{array}{l}\text { OR }(95 \% \\
\text { CI })^{\mathrm{a}}\end{array}$ & $P$ value \\
\hline \multicolumn{5}{|l|}{ Musculoskeletal } \\
\hline Arthralgia & $172(49.1)$ & $58,772(36.3)$ & $\begin{array}{l}1.70 \\
(1.34-2.16)\end{array}$ & $<0.001$ \\
\hline Carpal tunnel syndrome & $23(6.6)$ & $5985(3.7)$ & $\begin{array}{l}1.84 \\
\quad(1.13-2.98)\end{array}$ & 0.005 \\
\hline Osteoarthritis & $123(35.1)$ & $51,316(31.7)$ & $\begin{array}{l}1.17 \\
\quad(0.91-1.51)\end{array}$ & 0.160 \\
\hline Osteoporosis & $42(12.0)$ & $15,483(9.6)$ & $\begin{array}{l}1.29 \\
\quad(0.89-1.87)\end{array}$ & 0.119 \\
\hline Psoriatic arthritis & $16(4.6)$ & $8636(5.3)$ & $\begin{array}{l}0.85 \\
\quad(0.48-1.51)\end{array}$ & 0.531 \\
\hline Sjögren's syndrome & $20(5.7)$ & $3561(2.2)$ & $\begin{array}{l}2.70 \\
\quad(1.61-4.53)\end{array}$ & $<0.001$ \\
\hline Synovitis & $31(8.9)$ & $9864(6.1)$ & $\begin{array}{l}1.50 \\
\quad(0.98-2.29)\end{array}$ & 0.031 \\
\hline \multicolumn{5}{|l|}{ Respiratory } \\
\hline Chronic pulmonary disease & $93(26.6)$ & $26,694(16.5)$ & $\begin{array}{l}1.84 \\
\quad(1.40-2.41)\end{array}$ & $<0.001$ \\
\hline Pulmonary embolism & $16(4.6)$ & $1988(1.2)$ & $\begin{array}{l}3.86 \\
\quad(2.17-6.87)\end{array}$ & $<0.001$ \\
\hline \multicolumn{5}{|l|}{ Other } \\
\hline Cataract & $68(19.4)$ & $22,877(14.1)$ & $\begin{array}{l}1.47 \\
\quad(1.08-1.99)\end{array}$ & 0.005 \\
\hline General infection & $121(34.6)$ & $46,295(28.6)$ & $\begin{array}{l}1.32 \\
(1.03-1.70)\end{array}$ & 0.013 \\
\hline
\end{tabular}

$O R$ odds ratio, DMARD disease-modifying antirheumatic drug, $R C I$ repository corticotropin injection, $t s / b$ targeted synthetic/biologic

${ }^{a}$ Odds ratios and statistical significance determined by bivariate logistic regression with $\mathrm{RCI}$ initiation as the outcome with individual predictors. Relevant significant predictors and covariates were selected for inclusion in the full regression analysis

significantly lower mean number of fills compared with the non-RCI ts/bDMARD cohort (Fig. S1b). In addition to higher number of glucocorticoids tried and filled, a greater proportion of patients in the RCI cohort who took extended-use glucocorticoids had a significantly higher mean ADD compared with the non-RCI ts/bDMARD cohort $(21.20 \pm 25.60 \quad$ vs. $11.70 \pm 19.00, P<0.001$ ) (Fig. $4 \mathrm{a}, \mathrm{b}$ ). 


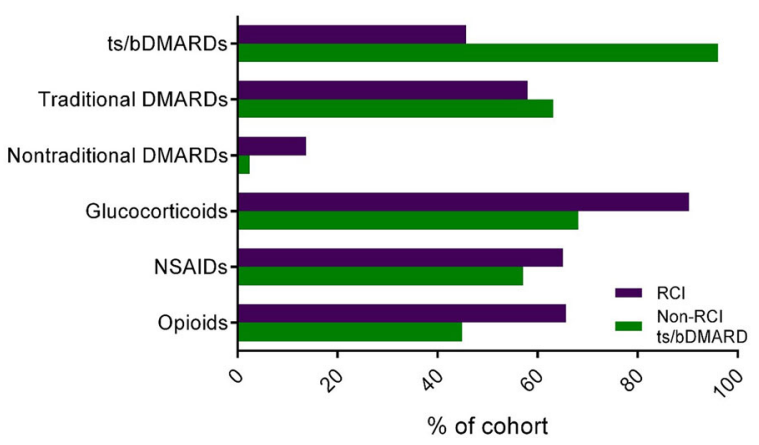

Fig. 2 Preindex (12-month baseline) medication usage patterns of ts/bDMARDs, traditional DMARDs, nontraditional DMARDs, glucocorticoids, NSAIDs, and opioids for the RCI and non-RCI ts/bDMARD full analysis cohorts. DMARD disease-modifying antirheumatic drug, $N S A I D$ nonsteroidal anti-inflammatory drug, $R C I$ repository corticotropin injection, $t s / b$ targeted synthetic/ biologic

Figure 5 summarizes the patterns of DMARD use in the RCI and non-RCI ts/bDMARD cohorts. The treatment pattern analysis for traditional DMARDs revealed a higher rate of hydroxychloroquine use in the RCI cohort and a higher rate of methotrexate use in the nonRCI ts/bDMARD cohort (Fig. 5a). The two cohorts had similar rates of leflunomide and sulfasalazine use. Among the nontraditional

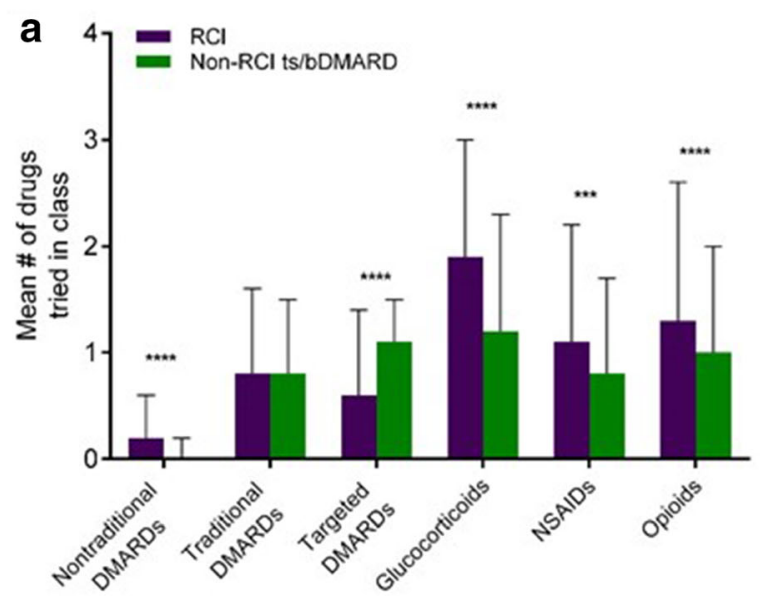

Fig. 3 Preindex (12-month baseline) mean number of drug classes tried (a) and mean number of claims/fills (b) within each drug class for the RCI and non-RCI ts/ bDMARD full analysis cohorts. DMARD disease-modifying antirheumatic drug, NSAID nonsteroidal anti-
DMARDs, the RCI cohort had a higher rate of azathioprine and mycophenolate mofetil use compared with the non-RCI ts/bDMARD cohort (Fig. 5b). With regard to the targeted DMARDs, the RCI cohort had a higher rate of use rituximab, tocilizumab, and tofacitinib and lower rates of use of abatacept and the TNF inhibitors as a class compared with the non-RCI ts/ bDMARD cohort (Fig. 5c).

\section{Healthcare Resource Utilization and Costs}

Table 3 summarizes HCRU during the preindex period. All-cause HCRU was higher for the RCI cohort in terms of the percentage of patients who had inpatient hospitalization (26 vs. $13 \%$ ) and $\mathrm{ED}$ visits (47 vs. $28 \%$ ) compared with the non-RCI ts/bDMARD cohort, respectively. Patients in the RCI cohort had a significantly higher mean number of inpatient visits ( 0.4 vs. 0.2 ), ED visits (1.4 vs. 0.5 ), office visits (18 vs. 12 ), and other outpatient visits (30 vs. 18) compared with patients in the non-RCI ts/ bDMARD cohort (all comparisons, $P<0.001$ ). The mean all-cause HCRU costs were higher in the RCI cohort compared with the non-RCI ts/ bDMARD cohort $(\$ 60,580$ vs. $\$ 46,026$, $P<0.001$ ) because of higher medical costs (\$38,468 vs. $\$ 22,360 ; P<0.001)$. No statistically

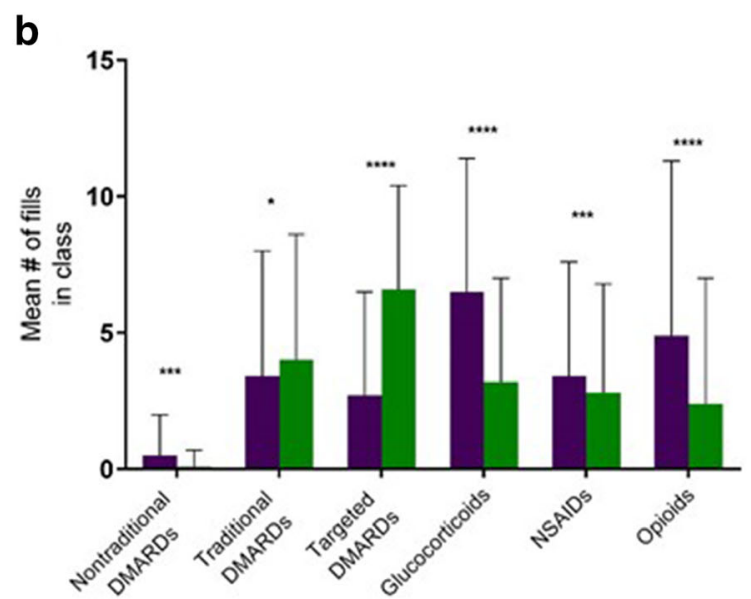

inflammatory drug, $R C I$ repository corticotropin injection, ts $/ b$ targeted synthetic/biologic. ${ }^{*} P<0.05$; ${ }^{* *} P<0.005$; ${ }^{* * *} P<0.001$ 


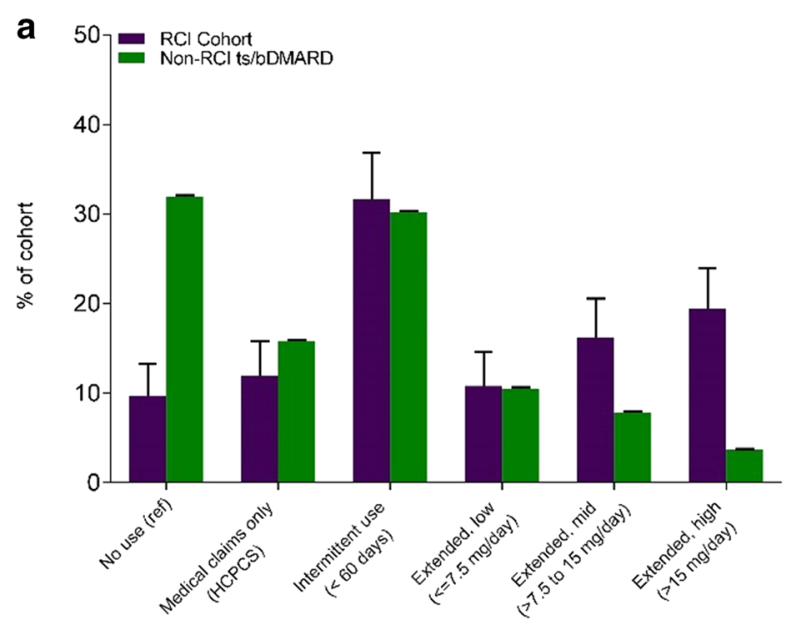

Fig. 4 Preindex (12-month baseline) glucocorticoid dosing patterns (a) and extended-use average daily dose (b) for the RCI and non-RCI ts/bDMARD full analysis cohorts. $D M A R D$ disease-modifying antirheumatic drug, HCPCS Healthcare Common Procedure Coding System, RCI

significant difference was noted in the mean cost of prescription fills in the RCI and nonRCI ts/bDMARD cohorts $(\$ 22,112$ vs. $\$ 23,666)$.

We also analyzed RA-related healthcare costs in the baseline period (excluding the index date), with RA-related defined as any claim with an RA diagnosis and/or an RA-related medication (i.e., csDMARDs, ts/bDMARDs, glucocorticoids, RCI). The RCI cohort had a higher numerical mean (SD) RA-related cost of inpatient hospitalization (\$1004 (\$8692) vs. \$625 $(\$ 5371)$ ) and ED visits (\$207 (\$1295) vs. \$121 (\$2176)) compared with the non-RCI ts/ bDMARD cohort, respectively. In contrast, the RCI cohort compared with the non-RCI ts/ bDMARD cohort had lower numerical mean (SD) RA-related pharmacy fills costs ( $\$ 8184$ $(\$ 13,440)$ vs. $\$ 20,962(\$ 19,099))$, medical costs $(\$ 8542(\$ 18,488)$ vs. $\$ 10,052(\$ 19,899))$, and total costs $(\$ 16,024 \quad(\$ 21,683)$ vs. $\$ 29,929$ $(\$ 21,387))$.

\section{Multivariable Analysis}

Table 4 summarizes the results of the multivariable logistic regression analysis for predictors of RCI initiation during the 12 months preindex in the full and subgroup analysis. See

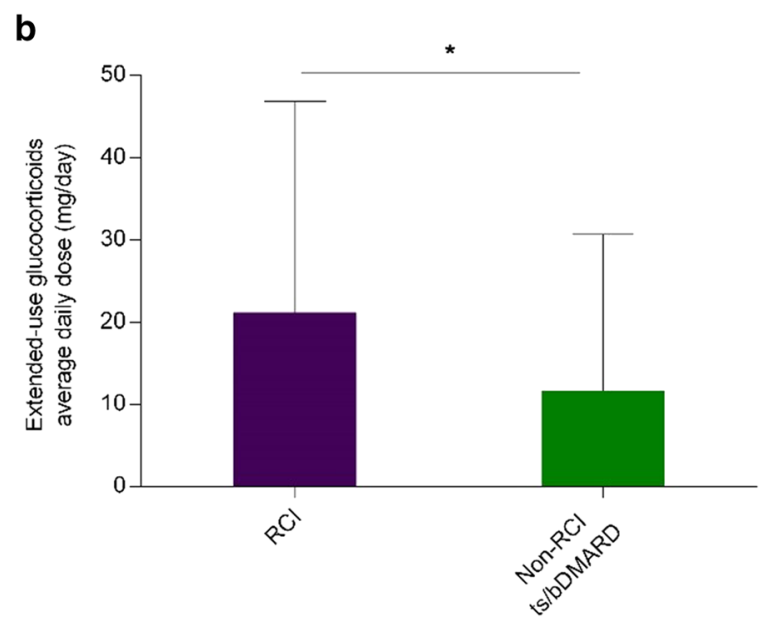

repository corticotropin injection, ref reference, $t s / b$ targeted synthetic/biologic. ${ }^{*} P<0.001$

the electronic supplementary materials to view the forest plots of the multivariable regression analysis in the full analysis set (Fig. S2) and subgroup analysis set (Fig. S3). In the full analysis set, glucocorticoids were the strongest predictors for RCI initiation, specifically for extended-use ( $\geq 60$ days $)$ high-dose $(>15$ $\mathrm{mg}$ /day) (odds ratio $(\mathrm{OR})=2.99 ; 95 \%$ confidence interval (95\% CI) 1.71-5.21), extended-use middose (> 7.5-15 mg/day) (OR 2.03; 95\% CI 1.18-3.49), and for intermittent use ( $<60$ days) at any dose (OR 1.67; 95\% CI, 1.04-2.67). These results remain consistent in the subgroup analysis set, with ORs for glucocorticoid use ranging from 2.27 to 4.38 . Use of nontraditional DMARDs was also a significant predictor of RCI initiation (OR 2.09; 95\% CI 1.20-3.65) in the full analysis set, but was not significant in the subgroup analysis set.

The most significant negative predictors of RCI initiation in the full analysis were the mean number of different ts/bDMARDs tried (OR 0.25 ; 95\% CI $0.19-0.33$ ) and the mean number of fills for ts/bDMARDs (OR 0.85; 95\% CI 0.81-0.89). Within the subgroup analysis, limited to those with a ts/bDMARD in the preindex period, the mean number of different ts/ bDMARDs tried became a significant predictor of RCI initiation (OR 1.82; 95\% CI 1.40-2.37), 

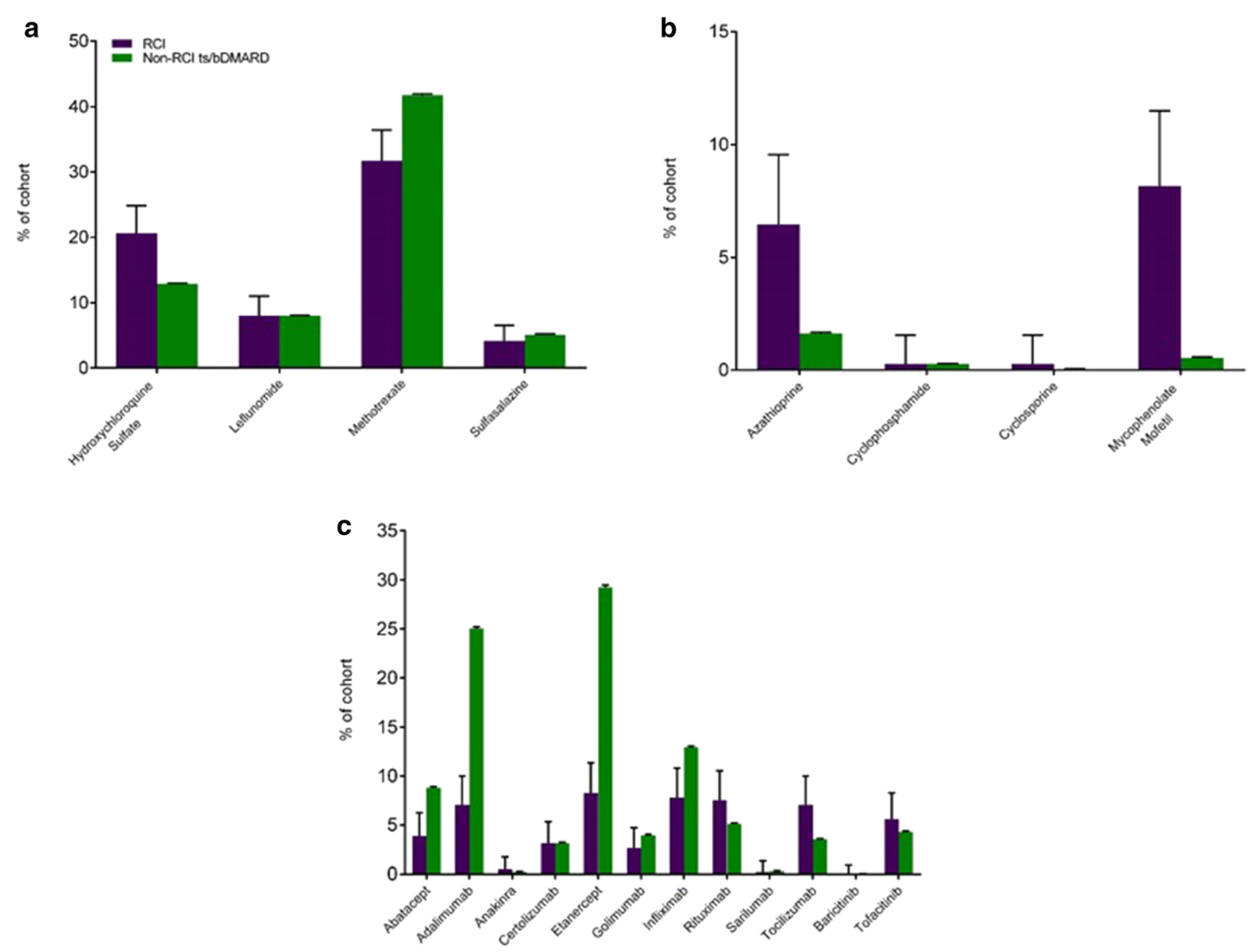

Fig. 5 Preindex (12-month baseline) usage patterns for traditional DMARDs (a), nontraditional DMARDs (b), and targeted DMARDs (c) for the RCI and non-RCI ts/bDMARD full analysis cohorts. DMARD disease-

while the mean number of ts/bDMARDs filled remained a negative predictor of initiation (OR 0.93; 95\% CI 0.89-0.97) similar to the full analysis set.

Among the comorbidities, anemia (OR 1.39; 95\% CI 1.05-1.83) and renal disease (OR 2.45; 95\% CI 1.64-3.66) were the only significant predictors of RCI treatment initiation in the regression analysis for the full analysis set. In the subgroup analysis set, anemia (OR 1.54; 95\% CI 1.04-2.29) remained as the only significant comorbid predictor of RCI treatment initiation. modifying antirheumatic drug, $R C I$ repository corticotropin injection, $t s / b$ targeted synthetic/biologic

\section{DISCUSSION}

We retrospectively compared medical and pharmacy claims data, during the 12-month preindex period, from a cohort of patients who had initiated RCI therapy versus a cohort treated with ts/bDMARDs without any claims for RCI. Evaluation of clinical characteristics, treatment patterns, and HCRU before initiation of RCI, versus initiation or continuation of ts/ bDMARD therapy, is critical in understanding differences in patients with uncontrolled RA requiring alternatives to standard therapy and in generating an accurate patient profile for RCI initiators. 
Table 3 Healthcare resource utilization (HCRU) in the preindex period for the full analysis set

\begin{tabular}{lccr}
\hline All-cause HCRU & RCI cohort $(\boldsymbol{n}=\mathbf{3 5 0})$ & Non-RCI ts/bDMARD cohort $(\boldsymbol{n}=\mathbf{1 6 2 , 0 6 5})$ & $\boldsymbol{P}$ value $^{\mathbf{a}}$ \\
\hline Inpatient hospitalization, $n(\%)$ & $90(25.7)$ & $20,435(12.6)$ & $<0.001$ \\
Number of visits, mean (SD) & $0.4(0.8)$ & $0.2(0.5)$ & $<0.001$ \\
Costs, mean (SD) & $\$ 9520(\$ 31,414)$ & $\$ 4292(\$ 23,812)$ & $<0.001$ \\
ED visits, $n(\%)$ & $166(47.4)$ & $45,235(27.9)$ & $<0.001$ \\
Number of visits, mean (SD) & $1.4(2.7)$ & $0.5(1.3)$ & $<0.001$ \\
Costs, mean (SD) & $\$ 2452(\$ 5560)$ & $\$ 921(\$ 4160)$ & $<0.001$ \\
Physician office visits, $n(\%)$ & $349(99.7)$ & $161,059(99.3)$ & 0.425 \\
Number of visits, mean (SD) & $18.1(10.0)$ & $11.5(7.8)$ & $<0.001$ \\
Costs, mean (SD) & $\$ 2193(\$ 1545)$ & $\$ 1422(\$ 1285)$ & $<0.001$ \\
Other outpatient visits ${ }^{\mathrm{b}}, n(\%)$ & $349(99.7)$ & $161,151(99.4)$ & 0.487 \\
Number of visits, mean (SD) & $29.9(21.6)$ & $18.1(16.2)$ & $<0.001$ \\
Costs, mean (SD) & $\$ 24,303(\$ 29,476)$ & $\$ 15,725(\$ 27,174)$ & $<0.001$ \\
Prescription fills, $n$ (\%) & $348(99.4)$ & $160,304(98.9)$ & 0.353 \\
Number of fills, mean (SD) & $56.3(34.1)$ & $45.4(32.3)$ & $<0.001$ \\
Costs, mean (SD) & $\$ 22,112(\$ 38,458)$ & $\$ 23,666(\$ 21,331)$ & 0.174 \\
Total costs, mean (SD) & & & $<0.001$ \\
Medical costs & $\$ 38,468(\$ 49,383)$ & $\$ 22,360(\$ 39,914)$ & \\
All costs & $\$ 60,580(\$ 60,558)$ & $\$ 46,026(\$ 42,103)$ & \\
\hline
\end{tabular}

$D M A R D$ disease-modifying antirheumatic drug, $E D$ emergency department, $N S$ not significant, $R C I$ repository corticotropin injection, $S D$ standard deviation, $t s / b$ targeted synthetic/biologic

${ }^{a} P$ values calculated from bivariate regression with RCI initiation as the outcome, with each independent variable for categorical variables and independent $t$ test for continuous variables

b Other outpatient visits include durable medical equipment; imaging; medication and related services; procedures; physician other services; tests; and occupational, physical, or speech therapy

Repository corticotropin injection is a complex mixture of adrenocorticotropic hormone analogs and other pituitary peptides that activates all five melanocortin receptors (MC1R-MC5R), inducing steroidogenesis, antiinflammatory effects, and direct immunomodulation of B and T cells [28-32]. Recently, Montero-Melendez et al. demonstrated activation of MC1R-induced cellular senescence in both synovial and dermal fibroblasts in a mouse model of inflammatory arthritis [33]. This MC1R-induced cellular senescence led to fibroblast proliferation arrest and upregulation of anti-apoptotic signaling with a pro-reparative phenotype, improving knee and joint damage scores by $35 \%$. The complex mixture of adrenocorticotropic hormones and pituitary peptides in RCI functionally activates the MCRs in preferential order, with the greatest activity observed on MC4R, MC3R, and MC1R signaling, followed by MC2R and a partial agonist effect on MC5R. This is distinct from synthetic adrenocorticotropic hormone (ACTH) 1-24, which shows greatest activity on MC2R, resulting in higher endogenous glucocorticoid production by $\mathrm{ACTH}_{1-24}$ compared with RCI [34]. 
Table 4 Multivariable logistic regression for predictors of RCI initiation in 12 months preindex

\begin{tabular}{|c|c|c|c|c|}
\hline \multirow[t]{2}{*}{ Predictors $^{a}$} & \multicolumn{2}{|l|}{$\begin{array}{l}\text { Full analysis set } \\
(n=162,415)\end{array}$} & \multicolumn{2}{|c|}{$\begin{array}{l}\text { Subgroup analysis set } \\
(n=155,833)\end{array}$} \\
\hline & $\overline{\mathrm{OR}(95 \% \mathrm{CI})}$ & $P$ value & OR (95\% CI) & $P$ value \\
\hline \multicolumn{5}{|l|}{ Treatment pattern } \\
\hline Traditional DMARDs tried & $0.88(0.70-1.09)$ & 0.234 & $1.07(0.79-1.44)$ & 0.672 \\
\hline Nontraditional DMARDs tried & $2.09(1.20-3.65)$ & 0.009 & $0.69(0.19-2.54)$ & 0.580 \\
\hline ts/bDMARDs tried & $0.25(0.19-0.33)$ & $<0.001$ & $1.82(1.40-2.37)$ & $<0.001$ \\
\hline Glucocorticoids tried & $1.05(0.91-1.22)$ & 0.470 & $1.11(0.91-1.36)$ & 0.303 \\
\hline NSAIDs tried & $0.94(0.80-1.10)$ & 0.434 & $0.97(0.76-1.22)$ & 0.772 \\
\hline Opioids tried & $1.08(0.95-1.23)$ & 0.245 & $1.03(0.85-1.24)$ & 0.769 \\
\hline Total claims for traditional DMARDs & $0.98(0.94-1.02)$ & 0.246 & $0.96(0.89-0.97)$ & 0.141 \\
\hline Total claims for nontraditional DMARDs & $1.03(0.88-1.19)$ & 0.742 & $1.17(0.87-1.59)$ & 0.294 \\
\hline Total claims for ts/bDMARDs & $0.85(0.81-0.89)$ & $<0.001$ & $0.93(0.89-0.97)$ & 0.003 \\
\hline Total claims for glucocorticoids & $1.09(1.05-1.13)$ & $<0.001$ & $1.09(1.04-1.14)$ & 0.001 \\
\hline Total claims for NSAIDs & $0.99(0.95-1.02)$ & 0.472 & $0.97(0.92-1.02)$ & 0.276 \\
\hline Total claims for opioids & $1.03(1.00-1.05)$ & 0.042 & $1.05(1.01-1.08)$ & 0.008 \\
\hline \multicolumn{5}{|l|}{ Glucocorticoid usage (reference, no use) } \\
\hline Intermittent use ( $<60$ days $)$ & $1.67(1.04-2.67)$ & 0.033 & $2.27(1.04-4.92)$ & 0.039 \\
\hline \multicolumn{5}{|l|}{ Extended use ( $\geq 60$ days) } \\
\hline Low dose $(\leq 7.5 \mathrm{mg} /$ day $)$ & $1.48(0.85-2.57)$ & 0.164 & $2.23(0.95-5.25)$ & 0.065 \\
\hline Mid dose ( $>7.5$ to $15 \mathrm{mg} /$ day) & $2.03(1.18-3.49)$ & 0.011 & $3.01(1.29-7.01)$ & 0.011 \\
\hline High dose ( $>15 \mathrm{mg} /$ day $)$ & $2.99(1.71-5.21)$ & 0.000 & $4.38(1.83-10.52)$ & 0.001 \\
\hline \multicolumn{5}{|l|}{ All-cause HCRU } \\
\hline Inpatient hospitalizations & $0.86(0.71-1.03)$ & 0.102 & $0.96(0.70-1.32)$ & 0.792 \\
\hline ED visits & $1.04(0.98-1.09)$ & 0.212 & $0.97(0.88-1.08)$ & 0.620 \\
\hline Office visits & $1.03(1.02-1.04)$ & $<0.001$ & $1.01(0.99-1.03)$ & 0.156 \\
\hline \multicolumn{5}{|l|}{ Clinical characteristics } \\
\hline CDMF-CCI & $0.79(0.70-0.89)$ & $<0.001$ & $0.89(0.75-1.05)$ & 0.153 \\
\hline CIRAS & $0.98(0.90-1.07)$ & 0.721 & $1.00(0.88-1.14)$ & 0.975 \\
\hline \multicolumn{5}{|l|}{ Comorbidities } \\
\hline Anemia & $1.39(1.05-1.83)$ & 0.020 & $1.54(1.04-2.29)$ & 0.030 \\
\hline Arrhythmia & $1.20(0.87-1.65)$ & 0.258 & $1.24(0.79-1.95)$ & 0.348 \\
\hline Arthralgia & $0.94(0.74-1.19)$ & 0.595 & $1.02(0.73-1.43)$ & 0.906 \\
\hline Carpal tunnel syndrome & $1.14(0.72-1.79)$ & 0.576 & $1.47(0.80-2.69)$ & 0.212 \\
\hline
\end{tabular}


Table 4 continued

\begin{tabular}{|c|c|c|c|c|}
\hline \multirow[t]{2}{*}{ Predictors $^{\mathrm{a}}$} & \multicolumn{2}{|l|}{$\begin{array}{l}\text { Full analysis set } \\
(n=162,415)\end{array}$} & \multicolumn{2}{|c|}{$\begin{array}{l}\text { Subgroup analysis set } \\
(n=155,833)\end{array}$} \\
\hline & OR (95\% CI) & $P$ value & OR $(95 \% \mathrm{CI})$ & $P$ value \\
\hline Cataract & $1.31(0.97-1.77)$ & 0.075 & $1.18(0.77-1.80)$ & 0.452 \\
\hline Cerebrovascular disease/stroke & $1.37(0.85-2.21)$ & 0.198 & $1.12(0.55-2.26)$ & 0.757 \\
\hline Chronic pulmonary disease & $1.20(0.90-1.62)$ & 0.218 & $1.10(0.73-1.68)$ & 0.642 \\
\hline Deep vein thrombosis & $1.52(0.81-2.84)$ & 0.189 & $1.29(0.49-3.38)$ & 0.604 \\
\hline Depression & $0.95(0.72-1.27)$ & 0.751 & $0.92(0.61-1.40)$ & 0.712 \\
\hline General infection & $0.93(0.73-1.18)$ & 0.531 & $0.88(0.62-1.24)$ & 0.462 \\
\hline Hypercholesterolemia, hyperlipidemia, triglyceridemia & $0.90(0.69-1.17)$ & 0.435 & $1.15(0.80-1.65)$ & 0.463 \\
\hline Hypertension & $1.05(0.81-1.36)$ & 0.706 & $0.78(0.54-1.13)$ & 0.188 \\
\hline Interstitial lung disease & $0.83(0.39-1.78)$ & 0.641 & $1.38(0.54-3.53)$ & 0.506 \\
\hline Ischemic heart disease & $1.24(0.87-1.75)$ & 0.233 & $1.54(0.95-2.51)$ & 0.081 \\
\hline Pulmonary embolism & $1.34(0.69-2.62)$ & 0.390 & $1.22(0.42-3.49)$ & 0.716 \\
\hline Sjögren's syndrome & $1.40(0.86-2.28)$ & 0.176 & $1.82(0.94-3.53)$ & 0.076 \\
\hline Synovitis & $1.04(0.70-1.53)$ & 0.859 & $1.16(0.69-1.96)$ & 0.574 \\
\hline Renal disease & $2.45(1.64-3.66)$ & $<0.001$ & $1.58(0.83-3.01)$ & 0.162 \\
\hline
\end{tabular}

CCI Charlson comorbidity index, CI confidence interval, CIRAS claims-based index of rheumatoid arthritis severity, $D M A R D$ disease-modifying antirheumatic drug, $E D$ emergency department, $H C R U$ healthcare resource utilization, $O R$ odds ratio, $R C I$ repository corticotropin injection, $S D$ standard deviation, $t s / b$ targeted synthetic/biologic

a The multivariable logistic regression for RCI initiation controlled for age, sex, region, insurance type, plan type, and index year

b The subgroup analysis was limited to patients in each cohort who had tried $\geq 1$ biologic DMARD in the 12 -month preindex period

This difference in MCR engagement and activation may explain the potential for RCI action through non-steroidogenic mechanisms. This is especially true for patients with refractory RA who are taking long-term and high-dose glucocorticoids and who demonstrate, with the addition of RCI treatment, a response that is unlikely to be explained by increased endogenous glucocorticoid production.

In addition to the mechanistic understanding of RCI efficacy, there is significant clinical evidence supporting the use of RCI treatment in patients with refractory RA following standard treatment recommended by current guidelines.
The safety and effectiveness of RCI therapy in RA has been shown in small single-arm studies [35-37] and in a two-part multicenter, randomized, placebo-controlled withdrawal trial in 259 patients with active RA [defined as Disease Activity Score with 28 joint count and erythrocyte sedimentation rate (DAS28-ESR) $>3.2$ ] despite treatment with a glucocorticoid and one or two DMARDs, including biologic DMARDs $[18,38]$. In the first part of the latter trial, all patients received twice-weekly open-label RCI for 12 weeks, at which point patients who achieved low disease activity (LDA; defined as DAS28-ESR < 3.2) were randomized to 12 more 
weeks of RCI or matching placebo [18]. At week $12,63 \%$ of patients achieved LDA $(P<0.0001)$, the primary endpoint of the trial, which was maintained at week 24 by $61 \%$ of patients in the RCI group and $42 \%$ in the placebo group $(P=0.019)$.

In this study, patients who had initiated RCI appeared to have greater disease severity with statistically higher mean CIRAS scores $(P<0.001)$, increased mean comorbidity index scores $(P<0.001)$, and a greater frequency of almost all individual comorbidities evaluated, including anemia, anxiety/depression, arrhythmia, arthralgia, chronic pulmonary disease, hypertension, and renal disease. The medication utilization analysis suggests that patients who initiated RCI had more recalcitrant or difficult-to-treat RA, as evidenced by higher use of nontraditional DMARDs, glucocorticoids, and opioids, and a higher proportion of patients trying more drug classes than patients who never initiated RCI. The hypothesis that RCI users had more difficult-to-treat RA compared with non-RCI ts/bDMARD users is corroborated by the higher all-cause HCRU, including inpatient hospitalization, ED visits, office visits, and outpatient visits as well as higher medical and total costs. Interestingly, we did not find a significant difference in total all-cause prescription refill costs that might be expected in comparison with patients using higher-cost ts/ bDMARDs, although significantly higher usage of other medication classes such as glucocorticoids, NSAIDs, and opioids may account for added costs before RCI initiation.

In the multivariable logistic regression analysis, glucocorticoid use was the clearest indicator of initiating RCI, especially extended use at medium and high doses, which had ORs of 2.03 $(P<0.01)$ and $2.99(P<0.001)$, respectively. As would be expected given the selection criteria, the non-RCI ts/bDMARD cohort had a higher rate of ts/bDMARD use compared with the RCI cohort. Our analysis cannot rule out the possibility that prior to the 12 -month preindex period examined in the study, patients in the RCI cohort had tried and not responded sufficiently to ts/bDMARDs, resulting in reliance on glucocorticoids and csDMARDs to control disease. The data demonstrating less TNF inhibitor use in the RCI cohort full analysis set might support this hypothesis. Given the FDA-approved indication for RCI as adjunctive therapy for shortterm administration in RA, as part of their rebate-eligible policy criteria, most payers require patients with RA to have tried glucocorticoids, a nonbiologic DMARD, and 1 additional DMARD (either conventional or targeted synthetic/biologic). When we limited the multivariable regression only to patients in each cohort with ts/bDMARD use in the preindex period (subgroup analysis set), the mean number of ts/bDMARDs tried flipped from a negative predictor of RCI initiation (OR 0.25 ; 95\% CI $0.19-0.33$ ) in the full analysis set to a significant positive predictor (OR 1.82; 95\% CI 1.40-2.37), while the mean number of total fills for ts/ bDMARD remained negative predictors of RCI initiation in both sets. Limiting the analysis to patients who had tried ts/bDMARDs in the preindex period suggests that, in comparison with patients who had not used RCI, those who had initiated RCI more often switched ts/ bDMARDs but failed to continue filling those prescriptions, indicating a possible lack of efficacy or tolerance. Patients in the RCI cohort in the full analysis set might have experienced this pattern of medication use, resulting in no ts/ bDMARD use in their preindex period.

Among the comorbidities tested in the multivariable logistic regression analysis, anemia and renal disease appeared to be significant predictors of RCI treatment initiation. Although causality cannot be confirmed, anemia may be a secondary marker of inflammation [39-43]. Renal disease may be secondary to RA, other comorbidities (e.g., cardiovascular disease, diabetes), or treatment with RA medications (e.g., NSAIDs) [44]. While the higher prevalence of anemia and arthralgia in the RCI cohort compared with the non-RCI ts/bDMARD cohort might be evidence of increased RA disease activity, and the renal disease may influence therapy selection, we also found other comorbidities (e.g., diabetes, deep vein thrombosis) to be more prevalent in the RCI cohort that are not known to be contraindications for many if not all targeted therapies.

Few other studies have analyzed predictors of treatment initiation in patients with RA, with 
this study being the first to identify predictors in the 12 months before initiating RCI. A health insurance claims study by Desai et al. reported that younger age, residence in the southern United States, being cared for by a rheumatologist, and having a health plan with more generous prescription drug benefits positively impacted treatment initiation with TNF inhibitors [24]. A medical chart review study by Nelson et al. found that patients with RA had received an average of 3.6 RA medications before initiating RCI, suggesting that RCI is administered primarily as a late-line therapy [16], which is supported by our findings of high nontraditional DMARD use in these patients. An analysis of 1998-2006 patient-reported data in the US Arthritis, Rheumatism and Aging Medical Information System database concluded that greater disability in the previous 6 months and previous use of glucocorticoids and DMARDs were independent positive predictors of initiation of treatment with biologics for patients with RA, whereas older age and lower annual income were independent predictors of decreased use of biologics [45]. Taking this a step further, our subgroup analysis demonstrated that even after initiation of ts/ bDMARDs, patients who started RCI treatment still had a higher comorbidity burden and continued to use glucocorticoids more frequently, for longer duration, and at higher doses.

\section{Strengths and Limitations}

The main strength of this study is capturing, from one of the largest proprietary US commercial claims databases, all patients who initiated RCI over a 10 -year period. This study was limited by the small sample size of the RCI cohort. Because of this small sample size, the only exclusion criteria we applied were limiting the data to adult patients, requiring 12 months of continuous enrollment before the index date, and excluding patients with the most extreme number of claims ( $>99.5$ th percentile) of the treatments of interest. We removed from drug treatment groups patients with $0.5 \%$ of the most extreme number of claims to prevent bias of unrealistic usage, such as 286 claims filled for opioids (with mean number of claims of 4.9 and 2.4 for RCI and non-RCI cohorts, respectively) or 165 claims for glucocorticoids (with mean number of claims of 6.5 and 3.2 for RCI and non-RCI cohorts, respectively) in the 12-month pre-index period. While we believe this was a reasonable approach, as more detailed information on these specific patients was unavailable in the claims data, it is not clear whether their removal impacted our results, although bivariate analysis between the two cohorts showed the same results with and without these patients included (data not shown). The study was also limited by the type of patient information available in claims databases. Because claims data did not include clinical measures of RA disease severity, such as the Clinical Disease Activity Index (CDAI) or DAS28, we used the previously published CIRAS as a surrogate measure, as described in the methods [22]. In the present analysis, cost estimates and HCRU are underestimated in patients with Medicare Supplemental coverage because claims data were captured only for the portion of the costs and usage not fully covered by Medicare, since no claims would be submitted through the supplemental plan for services fully covered by Medicare. Because the study population was limited to members who were commercially insured or had a Medicare Supplemental health plan, the results may not be generalizable to persons with government-sponsored health insurance or who are uninsured or underinsured.

\section{CONCLUSIONS}

Patients with RA who had initiated RCI therapy had more severe disease (indicated by higher CIRAS score; higher comorbidity burden; greater use of glucocorticoids, opioids, and NSAIDs; and higher HCRU) compared with non-RCI initiators using ts/bDMARD therapy. The most significant predictors for RCI therapy initiation in patients with RA were intermittent use of glucocorticoids at any dose, extended-use high-dose glucocorticoids, use of nontraditional DMARDs, and comorbidities of anemia and renal disease. 


\section{ACKNOWLEDGEMENTS}

The authors thank Huanxue Zhou for input on the early study design and analytic assistance, and they thank Elaine Boing and George Wan for their review and input on the manuscript.

Funding. Mallinckrodt Pharmaceuticals, Bedminster, NJ, USA, funded sponsorship of this study and the journal's Rapid Service Fee. All authors had full access to all the data used in this study and take responsibility for the integrity of the data and accuracy of the data analysis.

Medical Writing and Editorial Assistance. The authors thank Monica Nicosia, PhD, of Global Outcomes Group, Reston, VA, USA, for medical writing assistance and Melissa $\mathrm{L}$. Bogen, ELS, of Global Outcomes Group, Reston, VA, USA, for editorial assistance. This assistance was funded by Mallinckrodt Pharmaceuticals, Bedminster, NJ, USA.

Authorship. All named authors meet the International Committee of Medical Journal Editors (ICMJE) criteria for authorship of this manuscript, take responsibility for the integrity of the work as a whole, and have given final approval for the version to be published.

Disclosures. Kyle Hayes is an employee of Mallinckrodt Pharmaceuticals, Hazelwood, MO, USA. Mary Panaccio is a paid independent consultant for Mallinckrodt Pharmaceuticals. Niti Goel has a faculty appointment at Duke University School of Medicine, Durham, NC, USA, and acts as an independent consultant for Mallinckrodt Pharmaceuticals. Mohammed Fahim is an employee at KMK consulting and a paid analyst for Mallinckrodt Pharmaceuticals. At the time of this writing, all the authors declare that they have no other conflicts of interest.

Compliance with Ethics Guidelines. This article is based on previously existing observational data, and the research did not involve any new interventional studies of human or animal subjects performed by any of the authors. This retrospective study used deidentified data, and no personal health information was collected. For this type of study, formal consent is not required. Because of the retrospective study design using previously collected deidentified data, institutional review board approval was not necessary for this study.

Data Availability. The datasets generated during and/or analyzed during the current study are not publicly available because they are proprietary administrative health claims data owned by IBM.

Open Access. This article is licensed under a Creative Commons Attribution-NonCommercial 4.0 International License, which permits any non-commercial use, sharing, adaptation, distribution and reproduction in any medium or format, as long as you give appropriate credit to the original author(s) and the source, provide a link to the Creative Commons licence, and indicate if changes were made. The images or other third party material in this article are included in the article's Creative Commons licence, unless indicated otherwise in a credit line to the material. If material is not included in the article's Creative Commons licence and your intended use is not permitted by statutory regulation or exceeds the permitted use, you will need to obtain permission directly from the copyright holder. To view a copy of this licence, visit http://creativecommons.org/licenses/by$\mathrm{nc} / 4.0 /$.

\section{REFERENCES}

1. Smolen JS, Aletaha D, Barton A, et al. Rheumatoid arthritis. Nat Rev Dis Primers. 2018;4:18001.

2. Kawatkar AA, Jacobsen SJ, Levy GD, Medhekar SS, Venkatasubramaniam KV, Herrinton LJ. Direct medical expenditure associated with rheumatoid arthritis in a nationally representative sample from the medical expenditure panel survey. Arthritis Care Res (Hoboken). 2012;64:1649-56.

3. Murphy LB, Cisternas MG, Pasta DJ, Helmick CG, Yelin EH. Medical expenditures and earnings losses among US adults with arthritis in 2013. Arthritis Care Res (Hoboken). 2018;70:869-76. 
4. Yelin E, Murphy L, Cisternas MG, Foreman AJ, Pasta DJ, Helmick CG. Medical care expenditures and earnings losses among persons with arthritis and other rheumatic conditions in 2003, and comparisons with 1997. Arthritis Rheum. 2007;56: 1397-407.

5. Singh JA, Saag KG, Bridges SL Jr, et al. 2015 American College of Rheumatology guideline for the treatment of rheumatoid arthritis. Arthritis Rheumatol. 2016;68:1-26.

6. Smolen JS, Landewé RBM, Bijlsma JWJ, et al. EULAR recommendations for the management of rheumatoid arthritis with synthetic and biological disease-modifying antirheumatic drugs: 2019 update. Ann Rheum Dis. 2020;79:685-99.

7. Kearsley-Fleet L, Davies R, De Cock D, et al. Biologic refractory disease in rheumatoid arthritis: results from the British Society for Rheumatology Biologics Register for Rheumatoid Arthritis. Ann Rheum Dis. 2018;77:1405-12.

8. Desai RJ, Solomon DH, Jin Y, Liu J, Kim SC. Temporal trends in use of biologic DMARDs for rheumatoid arthritis in the United States: a cohort study of publicly and privately insured patients. J Manag Care Spec Pharm. 2017;23:809-14.

9. Atzinger CB, Guo JJ. Biologic disease-modifying antirheumatic drugs in a national, privately insured population: utilization, expenditures, and price trends. Am Health Drug Benefits. 2017;10:27-36.

10. Wabe N, Lee A, Wechalekar M, McWilliams L, Proudman S, Wiese M. Adherence to combination DMARD therapy and treatment outcomes in rheumatoid arthritis: a longitudinal study of new and existing DMARD users. Rheumatol Int. 2017;37:897-904.

11. Chambers JD, Wilkinson CL, Anderson JE, Chenoweth MD. Variation in private payer coverage of rheumatoid arthritis drugs. J Manag Care Spec Pharm. 2016;22:1176-81.

12. Yazdany J, Dudley RA, Chen R, Lin GA, Tseng CW. Coverage for high-cost specialty drugs for rheumatoid arthritis in Medicare Part D. Arthritis Rheumatol. 2015;67:1474-80.

13. Bonafede $\mathrm{M}$, Johnson $\mathrm{BH}$, Tang $\mathrm{DH}$, Harrison $\mathrm{DH}$, Stolshek BS. Compliance and cost of biologic therapies for rheumatoid arthritis. Am J Pharm Benefits. 2017;9:84-90.

14. Hifinger $M$, Hiligsmann $M$, Ramiro S, et al. Economic considerations and patients' preferences affect treatment selection for patients with rheumatoid arthritis: a discrete choice experiment among European rheumatologists. Ann Rheum Dis. 2017;76:126-32.

15. Acthar Gel (repository corticotropin injection). Prescribing information. Mallinckrodt. 2019. https://www.acthar.com/pdf/Acthar-PI.pdf. Accessed 5 Oct 2020.

16. Nelson WW, Philbin MJ, Gallagher JR, Heap K, Carroll S, Wan GJ. A retrospective medical record review of utilization patterns and medical resource use associated with repository corticotropin injection among patients with rheumatologic diseases in the United States. Rheumatol Ther. 2017;4:465-74.

17. Ho-Mahler N, Turner B, Eaddy M, Hanke ML, Nelson WW. Treatment with repository corticotropin injection in patients with rheumatoid arthritis, systemic lupus erythematosus, and dermatomyositis/polymyositis. Open Access Rheumatol. 2020;12: $21-8$.

18. Fleischmann R, Furst DE, Connolly-Strong E, Liu J, Zhu J, Brasington R. Repository corticotropin injection for active rheumatoid arthritis despite aggressive treatment: a randomized controlled withdrawal trial. Rheumatol Ther. 2020;7:327-44.

19. IBM. White paper: IBM MarketScan Research Databases for health services researchers. 2019. https:// www.ibm.com/downloads/cas/6KNYVVQ2. Accessed 30 Sept 2020.

20. United States Census Bureau. Census regions and divisions of the United States. 2010. https://www. census.gov/geographies/reference-maps/2010/geo/ 2010-census-regions-and-divisions-of-the-unitedstates.html. Accessed 20 Aug 2018.

21. Glasheen WP, Cordier T, Gumpina R, Haugh G, Davis J, Renda A. Charlson Comorbidity Index: ICD-9 update and ICD-10 translation. Am Health Drug Benefits. 2019;12:188-97.

22. Ting G, Schneeweiss S, Scranton R, et al. Development of a health care utilisation data-based index for rheumatoid arthritis severity: a preliminary study. Arthritis Res Ther. 2008;10:R95.

23. Andersen RM. Revisiting the behavioral model and access to medical care: does it matter? J Health Soc Behav. 1995;36:1-10.

24. Desai RJ, Rao JK, Hansen RA, Fang G, Maciejewski ML, Farley JF. Predictors of treatment initiation with tumor necrosis factor- $\alpha$ inhibitors in patients with rheumatoid arthritis. J Manag Care Spec Pharm. 2014;20:1110-20.

25. Chen SY, Choi CB, Li Q, et al. Glucocorticoid use in patients with systemic lupus erythematosus: association between dose and health care utilization 
and costs. Arthritis Care Res (Hoboken). 2015;67: 1086-94.

26. Rice JB, White AG, Johnson M, et al. Healthcare resource use and cost associated with varying dosages of extended corticosteroid exposure in a US population. J Med Econ. 2018;21:846-52.

27. Rice JB, White AG, Johnson M, et al. Quantitative characterization of the relationship between levels of extended corticosteroid use and related adverse events in a US population. Curr Med Res Opin. 2018;34:1519-27.

28. Patel HB, Bombardieri M, Sampaio AL, et al. Antiinflammatory and antiosteoclastogenesis properties of endogenous melanocortin receptor type 3 in experimental arthritis. Faseb J. 2010;24: 4835-43.

29. Olsen NJ, Decker DA, Higgins P, et al. Direct effects of HP Acthar Gel on human B lymphocyte activation in vitro. Arthritis Res Ther. 2015;17:300.

30. Wright D, Zweifel B, Sharma P, Galen K, Fitch R. Reduced steroidogenic activity of repository corticotropin injection (RCI) induces a distinct cytokine response following $\mathrm{T}$ cell activation in vivo. Ann Rheum Dis 2019;78(Suppl 2):1504 (abstr AB0082). http://ard.bmj.com/content/78/Suppl_2/1504.1. abstract.

31. Benko AL, McAloose CA, Becker PM, et al. Repository corticotrophin injection exerts direct acute effects on human B cell gene expression distinct from the actions of glucocorticoids. Clin Exp Immunol. 2018;192:68-81.

32. Decker DA, Grant C, Oh L, Becker PM, Young D, Jordan S. Immunomodulatory effects of H.P. Acthar Gel on B cell development in the NZB/W F1 mouse model of systemic lupus erythematosus. Lupus. 2014;23:802-12.

33. Montero-Melendez T, Nagano A, Chelala C, Filer A, Buckley CD, Perretti M. Therapeutic senescence via GPCR activation in synovial fibroblasts facilitates resolution of arthritis. Nat Commun. 2020;11:745.

34. Huang YJ, Galen K, Zweifel B, Brooks LR, Wright AD. Distinct binding and signaling activity of Acthar Gel compared to other melanocortin receptor agonists. J Recept Signal Transduct Res. 2020;2020:1-9.

35. Fischer PA, Rapoport RJ. Repository corticotropin injection in patients with rheumatoid arthritis resistant to biologic therapies. Open Access Rheumatol. 2018;10:13-9.
36. Gaylis N, Needell S, Sagliani J. The effect of corticotropin (ACTH 80 units weekly or biweekly) in combination with MTX in newly diagnosed RA patients from a clinical and structural perspective as measured by a CDAI score and osteitis, synovitis, and erosions on MRI. Ann Rheum Dis 2015;74(Suppl 2):1066 (abstr AB0503). http://ard. bmj.com/content/74/Suppl_2/1066.3.abstract. Accessed 12 Oct 2020.

37. Gillis T, Crane M, Hinkle C, Wei N. Repository corticotropin injection as adjunctive therapy in patients with rheumatoid arthritis who have failed previous therapies with at least three different modes of action. Open Access Rheumatol. 2017;9: $131-8$.

38. Fleischmann R, Furst DE. Safety of repository corticotropin injection as an adjunctive therapy for the treatment of rheumatoid arthritis. Expert Opin Drug Saf. 2020;2020:1-10.

39. Song SN, Iwahashi M, Tomosugi N, et al. Comparative evaluation of the effects of treatment with tocilizumab and TNF- $\alpha$ inhibitors on serum hepcidin, anemia response and disease activity in rheumatoid arthritis patients. Arthritis Res Ther. 2013;15:R141.

40. Wilson A, Yu HT, Goodnough LT, Nissenson AR. Prevalence and outcomes of anemia in rheumatoid arthritis: a systematic review of the literature. Am J Med. 2004;116(Suppl 7A):50S-57S.

41. Nissenson AR, Goodnough LT, Dubois RW. Anemia: not just an innocent bystander? Arch Intern Med. 2003;163:1400-4.

42. Peeters HR, Jongen-Lavrencic M, Raja AN, et al. Course and characteristics of anaemia in patients with rheumatoid arthritis of recent onset. Ann Rheum Dis. 1996;55:162-8.

43. Voulgari PV, Kolios G, Papadopoulos GK, Katsaraki A, Seferiadis K, Drosos AA. Role of cytokines in the pathogenesis of anemia of chronic disease in rheumatoid arthritis. Clin Immunol. 1999;92: 153-60.

44. Kapoor T, Bathon J. Renal manifestations of rheumatoid arthritis. Rheum Dis Clin N Am. 2018;44:571-84.

45. DeWitt EM, Lin L, Glick HA, Anstrom KJ, Schulman KA, Reed SD. Pattern and predictors of the initiation of biologic agents for the treatment of rheumatoid arthritis in the United States: an analysis using a large observational data bank. Clin Ther. 2009;31:1871-80. 